\title{
Toyohari Meridian Therapy: A Form of Acupuncture that Challenges our Assumptions while Opening New Vistas for Explorations of Acupuncture
}

\author{
Kylie O'Brien ${ }^{1}$ and Stephen Birch ${ }^{2}$ \\ ${ }^{1}$ Victoria University, Melbourne \\ 2Stichting (Foundation) for the Study of Traditional East Asian Medicine (STEAM), \\ Amsterdam \\ ${ }^{1}$ Australia \\ ${ }^{2}$ The Netherlands
}

\section{Introduction}

Toyohari Meridian Therapy (TMT) [東洋はり] evolved in Japan in the second half of the last century. Originally developed and practised primarily by blind acupuncturists, its theoretical basis lies in historical Chinese medical traditions [Birch, Felt 1999, Fukushima 1991]. Choice of acupuncture points is predominantly guided by Five Phase (Element) Theory. However, there is a startling difference between TMT and current Chinese traditional forms of acupuncture in terms of needling technique. Needles are not usually inserted in the 'root treatment' of TMT- instead, the qi is manipulated at the surface of the skin, with the tip of the needle only very lightly touching or not touching the skin in most cases. Another difference from current Chinese acupuncture is the notion, in TMT, that acupuncture points or acupoints are dynamic- their actual location whilst based on traditional notions of where acupoints are located anatomically as espoused by most modern acupuncture texts may differ slightly from the purported anatomical location. A key skill of the TMT practitioner is locating the acupoints, via the sense of touch using the lateral corner of the index finger near the fingernail. Once the 'live' acupoint is located, the practitioner forms a circle with their index finger and thumb, termed the 'oshide', at the surface of the skin, lightly touching the patient's body. The needle shaft is then inserted between the practitioner's thumb and forefinger so that the tip is above the acupoint, with the practitioner's thumb and forefinger grasping the needle shaft, whilst the handle of the needle is lightly held in the other hand. The practitioner then awaits the arrival of qi and applies particular needling techniques, depending on whether the aim is to supplement or drain.

Diagnosis of the primary pattern (sho) and secondary sho depends on synthesis of data from a case history, abdominal diagnosis and pulse diagnosis. Unlike in traditional Chinese medicine, tongue diagnosis is not a feature of TMT. Abdominal diagnosis involves palpation of the skin and wall of the abdomen. The five phases and their corresponding 
zang organ-meridian correspondences are mapped onto specific regions of the abdomen. The meridians are also palpated on the lower arm and lower leg. Pulse diagnosis is relied on heavily to guide the practitioner not only in initial diagnosis of the primary 'sho' or pattern of disharmony (as well as secondary pattern of disharmony) but during the actual treatment, giving the practitioner vital feedback on the effect of their needling technique on the patient's system. The Kozato technique is a technique developed to provide practitioners with feedback on their needling techniques by working in teams, with at least one person palpating the radial pulse and providing verbal feedback on the change to the quality of the pulse (depth, speed, force) whilst the practitioner feels for the acupoint, and performs the needling. The technique is a valuable aid to training of TMT practitioners.

Interest is growing in this unique form of Meridian Therapy, particularly in western countries. Many sighted practitioners now practice TMT in Australia, the US and Europe and various textbooks in English have aided the training of those outside Japan. Scientific research into TMT has begun, including investigations into the reliability of TMT diagnosis and the physiological correlates of pulse changes felt by the practitioner. How acupuncture works has still not been conclusively established. However, the way in which the mindbody is described by forms of Traditional East Asian Medicine (TEAM), such as Chinese medicine, is underpinned by a very different paradigm to that underpinning the biomedical model of the mind-body. One could argue that the Chinese medicine view of the mind-body is a kind of 'energetic' model (Ayurvedic medicine also has its own energetic model of the mind-body). There are inherent difficulties in trying to explain how systems of medicine such as Chinese medicine and therapies such as TMT work using a biomedical framework since they are such different paradigms. Clearly something else is going on in TMT that may not due to the physical stimulation of proprioceptors or the triggering of a neurochemical response in the same way as may occur with current forms of Chinese acupuncture since it doesn't typically involve insertion of the needle. TMT may also offer unique opportunities for exploring the scientific basis of traditional forms of acupuncture; Manaka postulated twenty five years ago that for research to examine the traditional East Asian concepts and descriptions of the body and how to treat patients, it may be necessary to use low-level stimulus input methods in order to maximise our ability to capture the effects of those systems [Manaka, Itaya 1986, Manaka et al. 1995].

This chapter will cover the origins of Toyohari Meridian Therapy, its theoretical basis, techniques used in diagnosis, and treatment protocols and approaches. It will also explore some of the scientific research into TMT with discussion on the directions of future research.

\section{Historical development}

The term 'Meridian Therapy' [経絡治療] refers to a traditional style of acupuncture that emerged in Japan in the late 1930s [Birch, Felt 1999, Fukushima 1991, Shudo 1990]. By 1913 modern Western style medicine had come to dominate in Japan and traditional forms of acupuncture had become severely limited through government regulations [Birch, Felt 1999, Locke 1980, Manaka et al. 1995, Shudo 1990]. Meridian Therapy evolved during similar period that the modern Chinese 'traditional Chinese medicine' [中醫], TCM acupuncture evolved, subjected to different political and historical pressures and influences [Birch, Felt 1999, Scheid 2002, Sivin 1987, Taylor 2004, Unschuld 1985]. Meridian Therapy emerged out of a period of careful investigation of the classical literature where the founding members of 
the Meridian Therapy movement, such as Sorei Yanagiya, Keiri Inoue, and Sodo Okabe, tried and tested different interpretations of the classics until they found a model with methods that appeared to work and was reproducible. This style like other traditional forms of acupuncture such as the current TCM style in China is based on interpretations and attempted reproductions of the historical literatures of acupuncture [Birch in preparation, Birch, Felt 1999]. The field of acupuncture has always manifested different traditional styles of acupuncture following different interpretations of the 'traditional' texts such as the Huangdi Neijing [黃帝內經] and Nanjing [難經] [Birch, Felt 1999, Birch, Lewith 2007, Goldschmidt 2009, Scheid 2002, Unschuld 1985, 1986, 2003], no less so today than historically [MacPherson, Kaptchuk 1997, Schnyer et al. 2007].

The earliest texts describing acupuncture date from around the first to second centuries BCE [Lo 2001, Unschuld 2003]. They take as a focus a model of the body very different from models that developed in Europe at that time or in later millennia in the West [Kuriyama 1999]. The core model that we find in these historical texts is one of the body containing twelve jingmai [經脈] meridians or channels, which circulate qi [氣] around the body to help keep the body's normal physiology intact and to help protect the body from disturbing influences [Unschuld 2003]. One of the earliest texts on acupuncture, the Huangdi Neijing Lingshu [黃帝內經靈樞] (hereafter the Lingshu), gives a kind of definition of (traditional) acupuncture: chapter seventy-five describes needling as a method for "regulating qi" [調氣] [Rochat de la Vallee 2006:79]. Acupuncture needles are applied to specific locations on the jingmai, the xue [穴] acu-holes or acupoints. The Lingshu describes the acu-holes in ways that are contrary to the preconceptions of people in the modern period, influenced by modern anatomical models of the body [Sivin 1987]. Of the acu-holes the Lingshu tells us that there are three hundred and sixty five locations where the qi travels in and out of the body and that the nature of these are not of the skin, flesh, sinews or bones, ie are not anatomical in origin or nature. Of this Sivin comments "a modern Westerner expects these points of communication, where the physician's needles can affect the circulation, to be places in tissue, but here we find them related instead to processes" [Sivin 1987:51].

TMT, following the focus of the Meridian Therapy movement, placed significant focus on ideas and methods that are described in the Nanjing [Shudo 1990]. Five phase classifications and correspondences are extensively used to help with classification of findings and observations. Radial pulse and abdominal palpations are given priority and exhibit development and refinements to help with choosing the correct diagnosis and treatment. Simple patterns based on reading of Nanjing sixty-nine form the core of the process of pattern recognition and treatment. This chapter of the Nanjing provides a basis for selecting on which meridians to direct treatment and which acupoints on the meridians to treat [Fukushima, 1991, Ono 1988, Shudo 1990]. The primary patterns or 'sho' are the primary targets of the 'root treatment' (in Japanese 'honchiho', in Chinese 'zhibenfa' [治本法]). The root treatment focuses on correcting underlying disturbances of qi circulation among the twelve meridians regardless of the nature and location of symptoms. The theory of Nanjing sixty-nine states that one should always apply supplementation, bu [補] before draining, xie [寫] techniques [Fukushima 1991, Shudo 1991, Unschuld 1986:583], practically interpreted in Meridian Therapy to mean focus on finding what is $x u$ [虛] or vacuous and take that as the primary target or first step of treatment. Nanjing sixty-nine also says 'for conditions of $\mathrm{xu}$, vacuity, bu, supplement the mother. This is understood to mean, for example if the lung (metal) is $\mathrm{xu}$, vacuous, one should supplement the spleen (earth) since earth if the mother of 
metal. This led to the identification of a few primary patterns formed by looking for weakness in two consecutive channels in the five-phase engendering cycle [Shudo 1990] see Table one. Then after carefully selecting the 'pattern' of which meridians to focus on (see Table 1) the supplementation technique [補法] is applied to acupoints on those two channels.

\begin{tabular}{|l|l|l|}
\hline Primary patterns or sho & Two meridians involved & $\begin{array}{l}\text { Five-phase engendering } \\
\text { cycle relationship }\end{array}$ \\
\hline Lung vacuity sho & Lung and spleen both weak & Earth is the mother of metal \\
\hline Spleen vacuity sho & Spleen and heart both weak & Fire is the mother of earth \\
\hline Liver vacuity sho & Liver and kidney both weak & Water is the mother of wood \\
\hline Kidney vacuity sho & Kidney and lung both weak & Metal is the mother of water \\
\hline
\end{tabular}

Table 1 . The primary patterns or sho

The Lingshu also described nine types of needles [Lu, Needham 1980:102-103], including the 'round-headed', yuanzhen [員銊] and blunt, shizhen [鍉銊] needles which were not inserted into the body or through the skin, but were instead applied on the surface of the body to influence the qi of the patient [Birch in preparation, Birch, Ida 1998:48-54]. Thus, while it may seem unusual today to talk of an acupuncture system such as TMT where the needles are not inserted, we can see historical precedents dating back over two thousand years in China. TMT is not alone as a system of acupuncture that routinely uses non-inserted needling methods; other systems can easily be found [Kobayashi 2008, Ono 1988].

There is an important concept in traditionally based forms of acupuncture, that for needling to be successful, the qi must arrive at the needle. The more common term used for this in modern literature is 'deqi' [得氣] meaning to 'obtain the qi', though another term is found commonly in the early historical texts, 'qizhi' [氣室], the 'arrival of qi'. Today the more common understanding of deqi is that it refers to sensations that the person being needled might experience, such as 'throbbing, aching, tingling' etc [Anon 1980, Cheng 1987]. However the early descriptions of these two terms either explicitly refer to them as sensations that the practitioner feels (see Nanjing seventy-eight [Unschuld 1986:635] or require mastering skills in order for the qi to arrive that cannot locate the sensations in the patient, so that it is as much about the level of inner development of the practitioner as it is about the manipulations of the needle [Birch 2004, Birch in preparation, Chace 2006, Chace, Bensky 2009, Yang 2007]. TMT, like its progenitor Meridian Therapy, takes the idea from the Nanjing that it is the superior physician that feels the qi with their left hand as the standard to which the practitioner should aspire [Fukushima 1991, Shudo 1990]. Thus there has been a significant focus in TMT on helping the student and practitioner develop the internal skills necessary to be able to reproduce the difficult needling techniques. In TMT the 'Kozato method' has played an important role in accelerating the development of learning of these skills. We can see dating from the earliest texts on acupuncture an idea that for the needling to be effective in its influences on the qi, the inner state of the practitioner (calm emotions, quiet mental focus, posture, state of relaxation etc) is important, thus we see other historical precedents for the TMT needling techniques. 
Although modern forms of acupuncture that have become more popular have focussed on inserting needles into relatively fixed anatomical locations on the body surface, focussing on physical movements and manipulations of the needle to produce therapeutic effects [Birch, Felt 1999, MacPherson, Kaptchuk 1997, Schnyer et al. 2007] we find the ample evidence dating from the earliest original texts of acupuncture for practice methods that use noninserted needling methods to non-anatomically based points on the body surface. In addition, the inner state of the practitioner is much more important than him/her being simply the person moving the needle. TMT is a system that has attempted to reproduce these early descriptions [Birch in preparation].

\section{TMT diagnosis and treatment}

Following the models of practice that became established in the general practice of Meridian Therapy in Japan, TMT places great emphasis on palpation of the radial pulses and the abdominal region in order to select the 'primary pattern' for root treatment [Birch, Felt 1999]. Through clinical experience reflex regions of the abdominal wall have been agreed upon as useful targets for diagnosis since they show clear changes reflecting problems in associated meridians. The method of palpation involved very softly stroking across the skin of the abdomen to see if there are changes of skin texture or temperature in those regions [Fukushima 1991]. Palpation of the radial pulses has been an important feature of TEAM since the Han dynasty [Lu, Needham 1980, Unschuld 1985, 1986]. Meridian Therapy has tended to follow methods for doing this introduced in the Nanjing [Fukushima 1991, Shudo 1990]. Two basic approaches are used in TMT, classifying the overall 'quality' of the pulses in relation to strength, speed and depth and palpating the three positions of the pulses that can be palpated in the region where they are described (along the radial bone, proximate to, over and distal to the styloid process) to examine differences in strength [Fukushima 1991]. After the patient has been questioned, the meridians that might be associated with the symptoms of the patients are palpated on the legs and arms. Following this the abdominal region is palpated and then the radial pulses are palpated. The pattern is most commonly decided by finding a concordance between the findings on the abdomen and the findings in the pulses. Specifically the region on the abdomen of that pattern must show signs of weakness and the positions of the two pulses associated with the pattern (see Table 1) must also be relatively weak. The symptoms and other findings of the patient may or may not match. This is an important issue to emphasise. In 'Understanding Acupuncture' the authors argued that the primary nature of diagnosis in traditional forms of acupuncture is to select treatment, not to describe an objectively existing 'disease' or 'disorder' [Birch, Felt 1999:218-222]. TMT is quite explicit about this, the phrase 'diagnosis is treatment' is taken as an expression of this idea. Thus the purpose of diagnosis is to help select the treatment. The treatment that is applied to the 'primary pattern' is, as was described above, part of the root treatment, 'honchiho' [本治法]). The principle purpose of this diagnosis is to help decide the best strategy for regulating the qi (tiao qi [調氣]. The findings of the abdominal and pulse position diagnosis are especially useful for deciding how best to do this on each patient. The general 'quality' of the pulse (depth, strength and speed) is used to help the practitioner judge how well the needling has been applied. These general qualities are not used to decide what treatment to apply. Rather, since they are thought to reflect something of the overall 
condition of qi in the patient, they are useful as indicating what kind of changes in the qi of the patient have been produced by the needling.

This focus on abdominal and pulse diagnosis in diagnosis is thus a natural point of focus for studies investigating TMT since if the findings are not consistent or there is poor agreement about them then a less than optimal treatment may be given to the patient. Further the emphasis on pulse quality changes is also a natural target for studies of TMT. The practitioner must be able to reliably judge them otherwise the foundation of practice and needling effects are of questionable value. We will see later that the first stages of research in TMT have examined these two issues. Once studies show that these aspects of diagnosis are valid, it then becomes possible to examine the TMT needling methods and treatments with more confidence that appropriate judgements about their choices and applications have been made, which is naturally the first step before any physiological or clinical studies can be conducted.

\section{TMT needling techniques}

The needling methods in TMT developed out of systematic efforts to reproduce historical Chinese descriptions of needling coupled with feedback by palpation among colleagues of how well each interpretation works [Birch, in preparation]. The notion of the non-fixed 'live' acupoints (where the location of the acupoint is not determined by anatomical location alone, but by the sensation in the practitioner's index finger on palpation along and/or near the meridian) is also based on efforts to examine and reproduce early historical Chinese literature.

Following traditional ideas TMT applies a supplementation needle technique (hoho [補法]) for deficient $(\mathrm{xu})$ conditions, draining (xie [寫]) needle techniques for replete, shi [實] conditions, as required according to the condition of the patient. Meridian Therapy in general has a relatively simple form of draining needle technique [Shudo 1990] while TMT currently has six different techniques according to what is felt in the pulses and how the overall condition is judged [Birch 2010, Fukushima 1991], while Ono had nine different techniques [Ono 1988]. Like other forms of traditional acupuncture, TMT also has a number of 'branch treatment' (Japanese hyochiho, Chinese zhibiaofa [治標法]) methods [Shudo 1990, 2003]). In TMT these branch treatments include 'naso' (treatment of the region of the suprclavicular fossa), 'muno' (treatment of the inguinal region), 'kikei' (a unique extraordinary vessel treatment method), 'shigo' (a method that employs the theory of 'midday-midnight') and a number of other simple needling or moxa methods [Fukushima 1990]. TMT treatment most often consists of a judicious combination of 'root' and 'branch' treatments to match each individual patient on the day of treatment.

Here we describe the supplementation technique (hoho [補法]). The following is a précis of more extensive descriptions currently in preparation [Birch in preparation]. In this needling method, the needle tip is held at the skin surface or perhaps touches the skin, it does not penetrate the skin. The methods described here cannot be learnt from textbooks but only through highly structured supervised training with regular feedback. In the Toyohari Association, one of the founders, Mr Kozato found that it is possible to monitor the radial pulses throughout the needling techniques and that based on the changes that are felt in the pulses, one can give continuous feedback to the technique. This is the 'Kozato hoshiki' or Kozato method [Fukushima 1990]. Given that the pulses ('mai' [脈]) were said to reflect the 
state of qi in the body and the theory of pulse diagnosis in the Nanjing informs that one can read the radial pulses to understand the condition of qi in the body and in the jingmai, meridians [Unschuld 1986], it is natural that one would feel the radial artery pulses to ascertain how well the needling has affected the condition of the qi. In the Kozato method, one can give feedback to every stage of the needling as different changes occur at each stage. A silver needle ( $40 \mathrm{~mm}$ long, $0.18 \mathrm{~mm}$ gauge) is used for this technique. After selecting the appropriate acupoint to be treated, the practitioner stands in the correct position relative to that acupoint. Holding the needle in the right hand (sashide), the practitioner places their left hand on the patient in order to find the acupoint. Touching very lightly the left index finger is softly and slowly stroked along the (flow of) meridian (jingmai) to be treated looking for the ('live') acupoint to be needled, paying attention to find signs of weakness to identify the exact location. The weak-feeling point has certain physical characteristics (is soft, loose, etc) but more subtle feelings are also detected, and the (experienced) practitioner becomes aware of something - touching or contacting the qi of the patient (at the 'live point'). After finding the exact ('live') location to be needled, and still touching very softly, the practitioner places the thumb of the left hand next to the index finger, pressing the pads of finger and thumb gently together directly over the acupoint to be supplemented. This forms the 'oshide'. In order to stabilise the oshide, the other fingers of the left hand are placed lightly so as to 'secure' the oshide. These movements are done all the while retaining the awareness of the qi at the point to be treated. The practitioner relaxes and adjusts their posture so as to relieve any unnecessary tension and then introduces the needle into the space between the index finger and thumb over the acupoint, angled along with the flow of the channel and directed towards the acupoint. Very carefully and slowly and the practitioner advances the needle tip towards the acupoint with their right hand (sashide) paying special attention to feeling when the needle tip contacts or engages something (contacts the qi). This can occur with the needle tip a small distance above the actual surface of the skin or at the skin surface. The practitioner feels this contact in their left hand (though other sensations elsewhere in their body may also be detected) [Birch 2004]. Once the practitioner has ascertained that the needle is at the correct 'depth' (here the language is depth within the flow of qi, not within the body), the right hand stops advancing the needle and holds the needle handle very softly while the left hand finger and thumb are pressed slightly more together (this is called 'sayuatsu' or 'left-right pressure' to seal the space around the needle tip to prevent qi leakage). Throughout these actions the practitioner remains calm and quietly focused noticing and relieving any tension that develops in their body. With the needle no longer advancing the practitioner seeks a change in the feeling (of qi) at the tip of the needle. If this change does not come automatically the practitioner may apply additional subtle manipulations with the right hand very gently until this change of feeling starts. As the change starts and the feeling (of qi - usually felt in the left hand) increases, the practitioner monitors it, then at the last moment increases the pressure of the left finger and thumb and as the patient inhales he rapidly removes the needle from the acupoint while simultaneously rolling the index finger or thumb over the acupoint (to close the 'hole' or space where the needle had been). The timing of this increased 'left-right pressure', needle removal and closure of the 'hole' is very precise and takes time to learn. The pressure is maintained on the acupoint for about one breath, then the digit is removed and the technique finished. 


\section{Challenges and questions posed by TMT needling methods}

Recent conclusions from among experts involved in acupuncture research are that we don't know the mechanisms of how acupuncture work, we have a lot of evidence of correlation between the application of needling techniques and measured physiological changes, but know little about the mechanisms inside the body [Hammerschlag, Zwickey 2006, Hammerschlag et al. 2007]. The neurochemical endorphin model is one attempt to describe how acupuncture analgesia works, for example [Pomeranz, Berman 2003]. Much acupuncture research has been based predominantly on the current biomedical model of the body. This particular model rests on certain fundamental underlying assumptions [Foss, Rothenberg 1987]. However, the way in which the mind-body is described by forms of TEAM, such as Chinese medicine, is underpinned by a very different paradigm to that underpinning the biomedical model of the mind-body [Birch, Lewith, 2007]. The Chinese medicine view of the mind-body is a kind of 'energetic' model. Ayurvedic medicine (Indian traditional medicine) and Tibetan medicine also have their own energetic models of the mind-body. There are inherent difficulties in trying to explain how systems of medicine such as Chinese medicine and therapies such as TMT work using a biomedical framework since they are underpinned by such different paradigms and it is necessary not to ignore these aspects.

It appears to us that something else is going on in TMT that may not be due to the physical stimulation of proprioceptors or the triggering of a neuro-chemical response in the same way as may occur with TCM style acupuncture, since TMT doesn't typically involve insertion of the needle. It manipulates the qi at the surface of the skin, often without even touching the skin. Typical TEAM acupuncture texts describe the meridians as pathways in which qi circulates, that traverse the skin as well as inside the body to connect with the related internal systems such as the zang-fu organs. Acupoints then are variously described as points on meridians (on the surface of the body) where the qi is accessible or concentrated. But what if the Chinese medical notion of the meridians extended above the body's physical surface, akin to how Ayurveda understands the body? In the Ayurvedic model of the body, the mind-body is envisaged as a series of energetic bodies, each enveloping the previous one and extending further out in space, vibrating at progressively higher frequencies. The physical body is the densest of the bodies, that is, vibrating at the lowest frequency compared with the others. Information is progressively stepped down from one energetic state (body) to another. These energetic bodies surrounding the physical body could be thought of as energetic templates for the physical body. They also provide a means by which information from the environment impacts on the human, and ultimately the means by which we are all connected. Disturbance in the energetic bodies may eventually lead to dis-ease in the physical body. For further descriptions of such models, the reader is referred to books by Gerber (Gerber 1988), Cousins (Cousins 2005) and McTaggart (McTaggart 2003).

Such theories of how the human mind-body works are not simply metaphysical ideals, for they are finding support in the areas of modern physics and biophysics. McTaggart's book 'The Field' describes a coherence of thought and experience amongst many scientists across the globe for the concept of an energy field that connects everything, termed the 'Zero Point Field' (McTaggart 2003). German scientist Fritz Popp has documented that all living things, including plants, animals and humans emitted a permanent current of photons (light), with humans emitting the lowest number compared with plants. In humans, these biophoton emissions follow biological rhythms with a high degree of coherence in healthy subjects 
[Popp 2002, Popp, Cohen 1997], whereas in subjects with cancer, the coherence and natural periodic rhythms was seen to be lost [Popp 2009]. He theorises that biophoton emissions are a kind of correction mechanism to minimise disturbances within the Zero Point Field. He further postulated that these bio-photon emissions play a central role in cell coordination and communication, that DNA is one of the most important stores of light and sources of biophoton emissions and that DNA may use frequencies as an information tool (McTaggart 2003, Popp, Nagel et al. 1984). Popp described how 97\% of DNA is associated with biophoton transmission and 3\% with genetic information (Cousens 2005). On this Cousens explains: 'The DNA communication of bio-photons communicates with the cells and sets the electromagnetic field for the cell to communicate with the rest of the body, with all the other cells, along with the intracellular matrix' (Cousens 2005). Here, we might be seeing a convergence of thought about the energetic nature of the body and traditional descriptions such as TEAM. Of course this area of theoretical linking needs much work and verification, but the similarities are suggestive and support the notion that we may need to take a different approach to investigating traditional practice methods such as acupuncture. Popp [McTaggart 2003, Popp et al. 2005] and colleagues have even found possible evidence linking his theories with those of acupuncture and suggested possible models for understanding this [Ho, Knight 1998].

So, in considering how TMT works, where are we to begin? It must be with the understanding that we begin any investigation with a set of assumptions about the nature of reality. In using western scientific research methodologies, underpinned by reductionism and mechanism, we need to acknowledge the inherent limitations as well as exploit the advantages of this style of inquiry. Whilst much has been written about the limitations of what is considered the gold standard of scientific research, the randomised controlled trial (RCT), scientific inquiry is not limited to RCTs and a range of other research methodologies are useful in investigating acupuncture. For a comprehensive description, the reader is referred to the book Acupuncture Research (MacPherson et al. 2007). We need to also remember that with particular models such as the biomedical and Chinese medical models, there is a language and set of theories that have developed to describe them, and such concepts are not always readily translatable across medical cultures. For example, the concept of 'qi' is particularly hard to define- more than fifty kinds of qi in the body and in nature are mentioned in the Huangdi Neijing Suwen [Leo 2011:105], Porkert lists thirty-two types of qi [Porkert 1974:167-173], and simply translating qi as 'energy' may fail to communicate the many nuances of the term 'qi' [Birch, Bovey in preparation, Felt 2008]. We feel it is necessary to expand the models of what we are doing when we attempt to research TEAM practice methods such as acupuncture and that seeking correlation with and using models from developing areas in physics and bio-physics may be helpful. This work will necessarily take some time. Thus as a first approach to investigating TMT we chose very basic and simple approaches rooted in its practice before attempting more elaborate basic science or clinical trial approaches. Our initial work is summarised in the next section.

\section{Some research findings in TMT}

The fact that TMT is so different from the more popular forms of acupuncture found today and yet, like other forms of traditional acupuncture such as TCM acupuncture is clearly based in the historical classics of acupuncture raises many issues for researchers interested in investigating acupuncture. It challenges the preconceptions of many about what 
constitutes the practice of acupuncture. It places the practice of pulse diagnosis at the heart of understanding both what do to in treatment and the condition of the patient both before and after needling has been done. It raises important questions about the relationship of needling and claims to have influenced the qi with a needle by bringing the practitioner much more into the picture than clinical and basic science investigations of acupuncture have permitted to date. It requires the development of models and then appropriate research methods that allow these aspects to be appropriately investigated.

In recent times, research has been conducted that has put TMT diagnosis under the microscope. In TMT treatment follows diagnosis. If diagnosis is not accurate, there can be less confidence that optimal treatment is received. Diagnosis in CM and TMT is, however, somewhat subjective. One way of ascertaining whether we have the correct diagnosis or not is to see if others agree with it (though it is possible of course to have several practitioners all agreeing on an incorrect diagnosis). Inter-rater reliability is a measure of the level of consistency of a measurement between two or more practitioners. Whilst there have been several studies investigating the inter-rater reliability of pulse, tongue diagnosis, other information collected in a CM examination and CM syndrome diagnosis ( $\mathrm{O}^{\prime}$ Brien and Birch 2009), few studies have focussed on TMT. An Australian study into the reliability of pulse diagnosis, abdominal (Hara) diagnosis and diagnosis of the primary and secondary sho between two experienced TMT practitioners conducted in 62 healthy Australians found a reasonable level of agreement for the basic pulse characteristics of depth (57\%), speed (61\%) and strength (77\%), and for two regions of the Hara using abdominal diagnosis $\left(\mathrm{O}^{\prime}\right.$ Brien et al. 2009). However level of agreement for the primary and secondary sho diagnoses was only $48 \%$ and $44 \%$ respectively, suggesting that there is room for improvement $\left(\mathrm{O}^{\prime}\right.$ Brien et al. 2009). This was the first study and only study to date to have comprehensively assessed inter-rater reliability in TMT. Earlier studies of the reliability of pulse diagnosis in Meridian Therapy found a variable level of agreement on basic pulse characteristics (Birch 1997), in one study ranging from no correlation to substantial to almost perfect correlation (Birch 1997).

TMT treatment relies heavily on pulse diagnosis. Changes in the pulse characteristics indicate to the practitioner that the treatment is complete. The practitioner is able to feel the difference in the quality of the pulse, but it is not known if there are any physiological correlates of these changes that can be measured objectively with medical instrumentation. To begin investigating this we initiated exploratory research in Australia to examine possible physiological correlates within the cardiovascular system of the pulse following a TMT root treatment ( $\mathrm{O}^{\prime}$ Brien et al. manuscript in preparation). The study was designed to see if the 'Sphygmocor' device, a standard tool in cardiovascular medicine, could detect changes that correlated with the reliable judgment of two practitioners that the radial pulses changed following a TMT root treatment. This is an example not only of cross-disciplinary research but also research seeking the intersections of knowledge between two medical systems.

Probably more than any other system of acupuncture, TMT helps highlight elements of treatment that are not usually made explicit during the teaching and description of needling methods that are very much based in the traditional historical literature on needling methods. This allows us not only to highlight and identify those elements but helps us rethink how we might go about constructing valid investigations of acupuncture methods that claim to be based in the traditional literature and models and which claim to work 
through their influences on the qi. One important aspect to highlight is that the mental state and more general inner state of the practitioner seem to be crucial for the needling to be successful. This raises a number of interesting and important possibilities that require ongoing work in model developments so that an expanded range of research strategies can be used to investigate a therapy like TMT acupuncture [Birch 2009, in preparation-a, in preparation-b].

\section{Conclusion}

TMT is a unique style of Meridian Therapy. Originally practised predominantly by blind Japanese practitioners, increasingly it is becoming popular amongst sighted practitioners and is now practised in many western countries. It requires a high degree of skill, not only in diagnosis, but also to locate the 'live' acupoint correctly and manipulate the acupuncture needle effectively. It challenges the practitioner to develop a very keen sensitivity of the sensation of touch in particular. TMT poses challenges in understanding how it may achieve its therapeutic outcomes, since in a root treatment typically the acupuncture needle does not touch the surface of the skin. The conventional biomedical model of how the body operates is likely to be superceded eventually by emergent models that describe the mind-body in terms of 'energy' and energy fields. Such models, based on quantum physics, are already developed and may provide a better framework from which to understand how TMT works. Chinese medicine, after all, could be described as an energetic model of the mindbody. It is important that research is conducted with a full awareness of the advantages and limitations of western scientific methodology, and of the underlying paradigms and assumptions upon which scientific research rests. TMT, like other forms of TEAM, has not stopped developing. It is therefore important that practitioners and researchers continue to put TMT 'under the microscope' and test it out in creative ways.

\section{References}

Anon (1980). Essentials of Chinese Acupuncture. Foreign Languages Press Beijing.

Birch S. Ph.D (1997). Thesis: "An exploration with proposed solutions of the problems and issues in conducting clinical research in acupuncture". University of Exeter.

Birch S (2004). Grasping the sleeping tiger's tail. NAJOM, Vol. 11, No. 32, pp. 20-23.

Birch S (2010). Chapter sixteen- Toyohari needling techniques. In Toyohari - East Asian Needle Therapy, European Branch of the Toyohari Association, UK, pp. 195-220.

Birch S (2009). Filling the whole in acupuncture. Part 1:1 What are we doing in the supplementation needle technique? European J Oriental Medicine, Vol. 6, No. 2, pp. 25-35. And Part 1:2, Vol. 6, No, 3, pp. 18-27.

Birch S. (In preparation-a). Filling the whole in acupuncture. Part 2: The 'treatment space' modeling the treatment process in acupuncture.

Birch S. (In preparation-b). Filling the whole in acupuncture - Part 3: researching acupuncture and traditional East Asian medicine (TEAM).

Birch S. The jing and qi - acupuncture perspectives. In Cabrer Mir MA, Birch S, Rodriguez M. (eds). The Jingmai \& Qi: Premedical and Medical Constructions and Uses. In preparation.

Birch S, Bovey M. Thoughts about the scientific investigation of concepts such as the jingmai and qi. Manuscript in preparation. 
Birch S, Cabrer Mir MA, Rodriguez M. Qi and the mind - explorations of the links between qi, the mind, mental and emotional states. In Cabrer Mir MA, Birch S, Rodriguez M. (eds). The Jing Mai \& Qi: Premedical and Medical Constructions and Uses. In preparation.

Birch S, Felt R (1999). Understanding Acupuncture, Churchill Livingstone, Edinburgh.

Birch S, Ida J (1998). Japanese Acupuncture: A Clinical Guide, Paradigm Publications, Brookline.

Birch S, Lewith G (2007). Acupuncture research, the story so far. In MacPherson $H$, Hammerschlag.R, Lewith G, Schnyer R (eds) (2007). Acupuncture Research: Strategies for Building an Evidence Base. Elsevier, London, pp. 15-35.

Chace C (2006). On greeting a friend, an approach to needle technique. Lantern, Vol.3, No. 3 , pp. :4-7.

Chace C, Bensky D (2009). An axis of efficacy. The range of meaning in chapter one of the Lingshu. Lantern, Vol. 6, No. 1, pp. 5-13 and Vol 6, No. 2, pp. 33-41

Cheng XN (1987). Chinese Acupuncture and Moxibustion, Foreign Languages Press, Beijing.

Cousens G (2005). Spiritual Nutrition. North Atlanctic Books, Berkeley, California.

Felt RO (2008). Is qi energy? Thieme Almanac 2008: Acupuncture and Chinese Medicine. George Thieme Verlag, Stuttgart, pp. 303-308.

Fukushima K (1991). Meridian Therapy, Toyo Hari Medical Association, Tokyo.

Goldschmidt A (2009). The Evolution of Chinese Medicine: Song Dynasty, 960-1200, Routledge, London.

Hammerschlag R, Langevin HE, Lao LX, Lewith G (2007). Physiological dynamics of acupuncture: correlations and mechanisms. In MacPherson H, Hammerschlag.R, Lewith G, Schnyer R (eds) (2007). Acupuncture Research: Strategies for Building an Evidence Base. Elsevier, London, pp. 181-197.

Hammerschlag R, Zwickey H (2006). Evidence based complementary and alternative medicine: back to basics. J Alt Complem Med. Vol. 12, No. 4, pp. 349-350.

Ho MW, Knight DP. The acupuncture system and the liquid crystalline collagen fibers of the connective tissues. Am J Chin Med, 1998:3-4:251-263.

Kobayashi S (2008). Acupuncture Core Therapy - Shakujyu Chiryo, Paradigm Publications, Taos.

Kuriyama S (1999). The Expressiveness of the Body and the Divergence of Greek and Chinese Medicine, Zone Books, New York.

Leo J (2011). Sex in the Yellow Emperor's Basic Questions, Three Pines Press, Dunedin..

Lo V (2001). The influence of nurturing life culture on the development of Western Han acumoxa therapy. In Hsu E, (ed). Innovation in Chinese Medicine (2001), Cambridge University Press, Cambridge, pp. 19-50.

Lock MM (1980). East Asian Medicine in Urban Japan, University of California Press, Berkeley.

Lu GD, Needham J (1980). Celestial Lancets, Cambridge University Press, Cambridge,

MacPherson H, Hammerschlag R, Lewith G, Schnyer R (2007). Acupuncture Research. Strategies for Establishing an Evidence Base. Churchill Livingstone, London.

Macpherson H, Kaptchuk TJ (1997). Acupuncture in Practice, Churchill Livingstone, New York.

Manaka, Y, Itaya K, “Acupuncture as intervention in the biological information system. (Meridian treatment and the X-signal system)," Address given at the annual 
assembly of the Japan Meridian Treatment Association, Tokyo, March 29-30, 1986. Published in English in the J Acup Soc New York 1994, Vol. 1, No. 3-4, pp. 9-18.

Manaka Y, Itaya K, Birch S (1995). Chasing the Dragon's Tail, Paradigm Publications, Brookline.

Mc Taggart L (2003). The Field, Element, Harper Collins Publishers, London.

O'Brien KA, Abbas E, Movsessian P, Hook M, Komesaroff PA, Birch S (2009). Investigating the reliability of Japanese Toyohari Meridian Therapy Diagnosis. J Alt Compl Med Vol. 15, No. 10, pp. 1099-1105.

O'Brien KA, Birch S (2009). A review of the reliability of traditional East Asian medical diagnoses. J Alt Complem Med, Vol. 15, No. 4, pp. 353-366.

O’Brien KA, Birch S, Abbas E, Movsessian P, Hook M, Komesaroff PA. Traditional East Asian Medical pulse diagnosis - a preliminary physiological investigation. [In preparation[.

Ono B (1988). Keiraku Chiryo Shinkyu Rinsho Nyumon. Yokosuka, Ido no Nippon Sha.

Pomeranz B, Berman B. Scientific basis of acupuncture (2003). In: G Stux, B Berman, B Pomeranz (2003). Basics of Acupuncture, fifth edition, Springer-Verlag, ,Berlin , pp $1-86$.

Popp FA (2002). Delayed luminescence of biological systems in terms of coherent states. Physics Letters A, pp. 293:93.

Popp FA (2009). Cancer growth and its inhibition in terms of Coherence. Electromagnetic Biology and Medicine, Vol. 28, pp.53-60.

Popp FA, Cohen S (1997). Biophoton emission of the human body. Journal of Photochemistry and Photobiology Biology, Vol. 40, pp. 187-189.

Popp FA, Nagl W, Li KH, Scholz W, Weingärtner O, Wolf R (1984). Biophoton emissionNew evidence for coherence and DNA as source. Cell Biophysics, Vol. 6, No. (1), pp. 33-52.

Popp FA, Maric-Oehler W, Schlebusch KP. Klimek W (2005). Evidence of Light Piping (Meridian-Like Channels) in the Human Body and Nonlocal EMF Effects. Electromagnetic Biology and Medicine, Vol. 24, No. (3), pp. 359-374.

Porkert M (1974). The Theoretical Foundations of Chinese Medicine. MIT Press, Cambridge.

Rochat de la Vallee E (2006). A Study of Qi in Classical Texts. Monkey Press, London.

Scheid V (2002). Chinese Medicine in Contemporary China., Duke University Press, Durham.

Schnyer R, Birch S, MacPherson H (2007). Acupuncture practice as the foundation for clinical evaluation. In MacPherson H, Hammerschlag.R, Lewith G, Schnyer R (eds) (2007). Acupuncture Research: Strategies for Building an Evidence Base. Elsevier, London, pp. 153-179.

Shudo D (1990). Introduction to Meridian Therapy. Eastland Press, Seattle.

Sivin N (1987). Traditional Medicine in Contemporary China. Centre for Chinese Studies, University of Michigan, Ann Arbor.

Taylor K (2004). Divergent interests and cultivated misunderstandings: the influence of the West on modern Chinese medicine. Soc Hist Med, Vol. 17, No. 1, pp. 93-111.

Unschuld PU (1985). Medicine in China: A History of Ideas. University of California Press, Berkeley.

Unschuld PU (1986). Nan Ching: The Classic of Difficult Issues. University of California Press, Berkeley. 
Unschuld PU (2003). Huang Di Nei Jing Su Wen - Nature, Knowledge, Imagery in an Ancient Chinese Medical Text. University of California Press, Berkeley.

Yang ZY (2007). On presence of mind and subtle sensations. The Lantern, Vol. IV, No.2, pp. 28-30. 


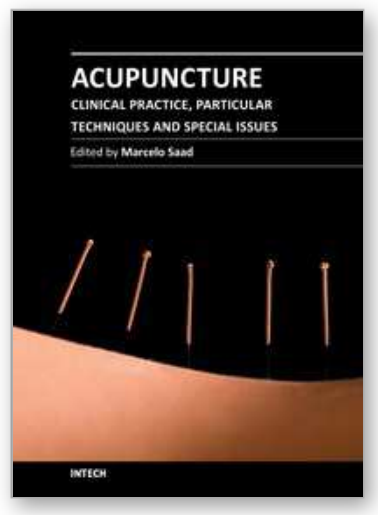

\author{
Acupuncture - Clinical Practice, Particular Techniques and Special \\ Issues \\ Edited by Prof. Marcelo Saad
}

ISBN 978-953-307-630-0

Hard cover, 138 pages

Publisher InTech

Published online 06, September, 2011

Published in print edition September, 2011

Acupuncture is growing in popularity world-wide. Acupuncture and related techniques are useful tools for treating a spectrum of diseases. However, there are still many areas of controversy connected to it due to the fact that mechanisms of action of acupuncture are not entirely clear. Another debilitating element is the absence of a convincing model of sham acupuncture for a control group in clinical trials. Therefore, there are still inappropriate prejudice and unfamiliarity regarding acupuncture. I hope this book can contribute to guide the advance of this ancient medical art. The reader will here find texts wrote by authors from different parts of the world. The chapters cover strategic areas to collaborate with the consolidation of the knowledge in acupuncture. The main objective is to share elements to make acupuncture more and better offered at health systems worldwide.

\title{
How to reference
}

In order to correctly reference this scholarly work, feel free to copy and paste the following:

Kylie O'Brien and Stephen Birch (2011). Toyohari Meridian Therapy: A Form of Acupuncture that Challenges our Assumptions while Opening New Vistas for Explorations of Acupuncture, Acupuncture - Clinical Practice, Particular Techniques and Special Issues, Prof. Marcelo Saad (Ed.), ISBN: 978-953-307-630-0, InTech, Available from: http://www.intechopen.com/books/acupuncture-clinical-practice-particular-techniques-andspecial-issues/toyohari-meridian-therapy-a-form-of-acupuncture-that-challenges-our-assumptions-whileopening-new-vi

\section{INTECH}

open science | open minds

\section{InTech Europe}

University Campus STeP Ri

Slavka Krautzeka 83/A

51000 Rijeka, Croatia

Phone: +385 (51) 770447

Fax: +385 (51) 686166

www.intechopen.com

\section{InTech China}

Unit 405, Office Block, Hotel Equatorial Shanghai

No.65, Yan An Road (West), Shanghai, 200040, China

中国上海市延安西路65号上海国际贵都大饭店办公楼405单元

Phone: +86-21-62489820

Fax: $+86-21-62489821$ 
(C) 2011 The Author(s). Licensee IntechOpen. This chapter is distributed under the terms of the Creative Commons Attribution-NonCommercialShareAlike-3.0 License, which permits use, distribution and reproduction for non-commercial purposes, provided the original is properly cited and derivative works building on this content are distributed under the same license. 